\title{
En un lugar del 'Quijote' (A propósito de algunas palabras y expresiones cervantinas) ${ }^{1}$
}

\author{
ABRAHAM MADROÑAL ${ }^{\star}$
}

Pocos libros más y mejor anotados que el Quijote, además desde fecha relativamente temprana. Editores sesudos como Clemencín a principios del XIX [1833-39], Schevill-Bonilla [1928-41] y Rodríguez Marín a principios del XX [1911, última ed. 1947-1949], o más recientemente Riquer [1944, última ed. 2004], Lerner-S. de Cortázar [1969, nueva ed. 2005], Murillo [1978], Gaos [1987], Sevilla-Rey [1994], Amorós [1999], Sevilla [2004], Pedraza [2004] o Rico [1998, última ed. 2005] han ido acumulando información para intentar explicar todos los lugares del texto que necesitaban aclaración. Destaca el rigor erudito con que se han solucionado los problemas; sin embargo, y como no puede ser de otra manera, la particular formación de cada uno de los lectores de la obra permite encontrar una serie de referencias que podrían añadirse a un libro de por sí ya bien anotado.

Por el contrario, los vocabularios dedicados a la obra no siempre se han hecho con ese rigor, de lo que resulta que muchas veces no se ha entendido del todo el léxico del Quijote. Podríamos mencionar el caso del Vocabulario de Cervantes de C. Fernández Gómez [1962], que es una obra útil, pero que como su mismo autor reconoce no deja de ser la aportación de un aficionado que simplemente da ejemplos de uso de las palabras en las obras de Cervantes, pero no las define. Como singularidad, halla Fernández Gómez que Cervantes utiliza 12372 palabras diferentes y hace un estudio estadístico del Quijote que arroja curiosos datos sobre las formas más usadas. El autor recoge los

* Instituto de la Lengua Española, CSIC.

1. Una versión resumida de este trabajo se leyó como conferencia en el curso "El Quijote ayer y hoy", celebrado por la Universidad Internacional Menéndez Pelayo en su sede de La Coruña, el 15 de julio de 2005. 
ejemplos debajo de cada uno de los lemas, sin ordenarlos por acepciones ni por ningún otro criterio, mezclando además los de las diferentes obras ${ }^{2}$.

Anterior en el tiempo es La lengua de Cervantes [1906], del meritorio pero controvertido Julio Cejador, que incorpora un diccionario del Quijote. Cejador sostenía que en su tiempo no se estudiaba en España el Quijote y por tanto se mantenían tópicos como que "Cervantes abunda en italianismos y está lleno de incorrecciones y descuidos", cosa que él niega terminantemente y desafía a cualquiera que intente encontrar estas procedencias en su diccionario. Por otra parte, critica a los literatos modernos, influidos por el francés y el latín (y pone como ejemplo a Valera), y señala: "el caudal más idiomático nuestro, el de origen ibérico o bascongado, [...] nos lo guardamos para hablar en casa", por eso él aporta buen número de etimologías vascas, que discrepan necesariamente con las que los romanistas extranjeros han dado para las palabras españolas. Es el suyo un diccionario copioso, en el que se recogen ejemplos de todas las palabras del Quijote (que el autor cifra en más de 9000 ). Aporta la etimología de cada una de las palabras y da ejemplos varios de su uso, a veces con breve comentario ${ }^{3}$.

Pero hay casos peores todavía en lo que se refiere al estudio del léxico del Quijote, autores que han prestado aún menos servicio al conocimiento de las palabras y expresiones que contiene. Tal es el caso del chileno Aníbal Echeverría, autor de un Vocabulario de la obra [1932]. El autor muestra un desconocimiento grande de la realidad definida, porque así por ejemplo define albar: "animalito casero doméstico, de color blanco", cuando la cita del Quijote es conejo albar, es decir, "blanco". Otras veces la definición misma es un disparate, tomado de algún diccionario, pero que no tiene nada que ver con el uso que hace Cervantes de la palabra. Es el caso de la voz badulaque, que define como "guisado de bofes, chanfaina, aceite compuesto de varios ingredientes y menudencias", cuando el texto del Quijote dice: "esotros badulaques y enredos y revoltillos, no se me acuerda ni acordará más dellos que de las nubes de antaño". Evidentemente la voz significa aquí 'lío, embrollo'. La definición de ballena no tiene desperdicio, para este lexicógrafo es "cada una de las láminas córneas que tienen en la mandíbula superior", sin embargo las dos veces en que aparece la palabra en la obra se refieren al animal, no a sus mandíbulas.

2. Además lleva a cabo una actualización ortográfica en los lemas (circunflexas, s/v circunflejo), pero respeta cirimonia, cobdicioso, agora / ahora, etc. con buen criterio, porque cita los textos por la primera edición (o del facsímil que de la misma llevó a cabo la Academia). Y a continuación suele poner entre paréntesis el término actual (codicioso), allombre (al hombre).

3. Algunas de esas etimologías son originales, pero disparatadas, como por ejemplo la voz hacha, que él hace derivar de un étimo vasco atch = roca, peña, porque dice que estos instrumentos se fabricaban con esos materiales en la época antigua, cuando hoy está aceptado su origen francés; o acurrucarse, que hace derivar del euskera gur = doblarse, cuando hoy se acepta su derivación de a + latín corrugare, "arrugar". Adarga dice probablemente del euskera adar = rama, no admite la etimología árabe. Aderezar lo hace derivar también del euskera Aderez= conforme a regla y no del latín $a+d i r e c-$ tiare, de directus. Adobar también del euskera $a d+o b a=$ mejorar. Y así sucesivamente. 
Al bocací le llama bocasí; al bagarino, bogarino (seguramente porque como define "remadores moros asalariados" pensaría que tal palabra venía de bogar); a las borracherías, bonacherías. Lo peor, sin embargo, no es eso, es que también inventa palabras, y sus correspondientes definiciones, que no aparecen nunca en la obra. Así por ejemplo, y sin salir de las dos primeras letras: barbilucho, que define como "barbilindo; hombre pequeño, afeminado, bien parecido; el que empieza a echar barbas". En el Quijote sólo aparece barbilucio. Lo mismo ocurre con tierra de tallo, en lugar de tierra de talle; torniscos, en lugar de torniscones, etc. Tampoco aparece birretones en el Quijote, palabra que define como "coches de dos ruedas"; pero no significa eso y no tenemos ningún ejemplo en la literatura española con ese sentido, aunque sí -desde 1619- con la acepción de "sombrero". Inventa también boguera, que define como "ventanico de los pájaros" y que no está en el Quijote; boche 'verdugo, en germanía'; bofordar, "derribar tablados, de a caballo, con lanza"; borgoñosa, "celada, que dejaba descubierto el rostro", velleras, 'mujeres que se ocupaban en depilar el vello', tesoro de duendes, 'la hacienda que se pierde sin saber cómo se ha gastado'; sábana, 'llanura' y un largo etcétera. Palabras, insisto, que nunca emplea Cervantes ni en el Quijote, ni en ninguna obra suya. Por tanto es una obra igual de fantasiosa y de ficción que la propia producción de Cervantes. Y la pretensión que tenía su autor: "formar un índice, claro y exacto, con las acepciones de las palabras de esta obra que necesitan alguna explicación" (p. 6) resulta ser de una ironía también propiamente cervantina.

Por supuesto, otras aproximaciones ha habido más recientes (y mucho más afortunadas) que se ocupan del estilo y la lengua, como las muy apreciables de Hatzfeld [1927, última ed. 1972] y Rosenblat [1971, última ed. ampliada 1995]; otras se dedican específicamente del vocabulario ${ }^{4}$. Estos libros han servido de base segura para anotar un libro inagotable.

He aquí algunas de esas notas que según mi parecer podrían añadirse a una edición del Quijote para facilitar su cabal entendimiento, para completarlo o, simplemente, para incorporar a su lectura algunos matices que contribuyen a dar trascendencia a determinadas palabras o expresiones. Por fortuna, las modernas herramientas de consulta han abierto hoy el campo a la hora de encontrar los ejemplos coincidentes. Muy especialmente el CORDE (Corpus Diacrónico del Español) de la Real Academia Española, pero también el NTLLE (Nuevo Tesoro Lexicográfico de la Lengua Española) o el TESO (Teatro Español del Siglo de Oro). Gracias a estos y otros auxilios, los investigadores disponemos de un ingente material de

4. Es el caso de El léxico del Quijote, de Juan Hernández Herrero [1996] o el Diccionario del Quijote, de Manuel LACARTA[1994] o la Enciclopedia del Quijote, de César VIDAL [1999, nueva ed. 2005], que aporta también localizaciones de las palabras o nombres tratados. Pero no agotan la materia, como es lógico si se tiene en cuenta la dimensión del objeto tratado. 
textos y diccionarios que hacen más fácil la tarea de cotejar las palabras 5 .

Como señalaba Ángel Rosenblat, a la altura de 1973: "La labor filológica de hoy consiste en devolverle la claridad meridiana de 1605, en explicar sus expresiones envejecidas y las alusiones hoy inactuales, en presentarlo tal como realmente fue y como debe seguir siendo" [1973: 355]. Una tarea que hoy -con las actuales ediciones- prácticamente se puede dar por acabada, pero en la que todavía es posible añadir algún detalle por mínimo que sea.

\section{DE LA ABUNDANCIA DEL CORAZÓN HABLA LA LENGUA}

Tal frase se encuentra en el capítulo 12 de la segunda parte. Dice así don Quijote, a propósito del Caballero del Bosque:

Escuchémosle, que por el hilo sacaremos el ovillo de sus pensamientos, si es que canta, que de la abundancia del corazón habla la lengua [II, 12, p. 788]

En este caso anota Rico, 2004 que se trata de una "frase proverbial que se remonta al Evangelio". Y cita un lugar de Mateo: "Ex abundatia cordis, os loquitur" (Mt 12, 34; Lc 6, 45).

La frase aparece también en Fray Martín de Córdoba, Juan Arce de Otárola, San Juan Bautista de la Concepción, fray Juan de los Ángeles o Quevedo y curiosamente figura como tópico en esa recopilación de la época que es la obra de Juan de Aranda, Lugares comunes de conceptos, dichos y sentencias: "De la abundancia del corazón habla la boca" (Sevilla, Juan de León, 1595, f. 148).

\section{BÁCULO DE SU VEJEZ}

Escuchamos a Dorotea, cuando describe ante don Quijote y otros la vida que llevaba con sus padres. La joven dice de estos que:

La mayor riqueza y nobleza que ellos se preciaban era de tenerme a mí por hija; y así por no tener otra ni otro que los heredase como por ser padres y aficionados, yo era una de las más regaladas hijas que padres jamás regalaron. Era el espejo en que se miraban, el báculo de su vejez y el sujeto a quien encaminaban, midiéndolos con el cielo, todos sus deseos,

5. Todas las referencias al Quijote se dan por la nueva edición de Francisco Rico (Galaxia Gutenberg-Círculo de Lectores-CECE, 2004). Las citas de las otras obras, cuando no aportan más datos que la página, remiten al citado Corpus Diacrónico del Español.

ANALES CERVANTINOS, VOL. XXXVII, PP. 141-165, 2005. ISSN: 0569-9878 
de los cuales, por ser ellos tan buenos, los míos no salían un punto [I, 28, p. 352]

Es un lugar que no suele anotar las ediciones modernas, pero la expresión báculo de su vejez la recogen algunos estudiosos casi contemporáneos, como Luis, Galindo en sus Sentencias filosóficas a mediados del XVII (tomo de la letra V, 94); también textos modernos como la Fraseología de Cejador, pero no hace más que remitir al anterior. Cervantes utiliza báculo al menos otra vez en la obra, refiriéndose a don Quijote como "báculo y consuelo de todos los desdichados".

Pero la expresión báculo de la vejez procede en última instancia de la Biblia:

Tobias vale patri et matri suae et ambulaverunt ambo simul cumque profecti essent coepit flere mater eius et dicere baculum senectutis nostrae tulisti et transmisisti a nobis numquam esset ipsa pecunia pro qua misisti eum sufficiebat enim nobis paupertas nostra ut divitias conputaremus hoc quod videbamus filium nostrum (Tobías 5, 22-25).

También en otro lugar, un poco más adelante:

Heu me fili mi ut quid te misimus peregrinari lumen oculorum nostrorum baculum senectutis nostrae solacium vitae nostrae spem posteritatis nostrae / omnia in te uno habentes te non debuimus dimittere ire a nobis (Tobías, 10, 4-5).

Que su origen esté en el texto bíblico no significa que Cervantes la tome directamente de él, como sí ocurre con otras citas ya señaladas por editores y estudiosos. Por ejemplo, es el caso de la frase "No se mueve la hoja del árbol sin la voluntad de Dios" que procede también del libro sagrado (Mateo 6, 25) y que Cervantes había utilizado más o menos igual en Rinconete y Cortadi$l l o^{6}$.

De donde muy probablemente Cervantes toma la cita es de las Epístolas familiares de Guevara, donde se puede leer:

El hijo de la Virgen estaba en la cruz puesto. ¡O madre desconsolada y o reina de consolación! Tú eres la que allí llorabas lágrimas irremediables, que no Anna la de Tobías, porque sus lágrimas llevaron remedio, mas las tuyas ni llevaron remedio ni aun hallaron consuelo. Con irremediables lágrimas lloraba la triste señora, pues ella, y no Anna, era la que perdía el báculo que para su vejez había criado, el espejo con que se miraba, la

6. "Pero tras este tiempo vendrá otro y habrá que hacer más de lo que quisiéremos; que no se mueve la hoja sin la voluntad de Dios, y no hemos de hacer nosotros que se vengue nadie por fuerza". Novelas ejemplares. Ed. Florencio Sevilla Arroyo; Antonio Rey Hazas. Alcalá de Henares, Centro de Estudios Cervantinos, 1994, p. 600. 
146 - ABRAHAM MADROÑAL

lumbre con que veía, el reposo a do descansaba, la esperanza que tenía y la cosa que más amaba ${ }^{7}$.

Por su parte, báculo es palabra que se documenta en castellano ya en 137679, en la Gran Crónica de Alfonso XI en su sentido recto; en 1499 Fernández de Santaella la recoge en acepción figurada como `apoyo de los flacos”: "Del Señor procede del palillo o báculo de la substentación de los flacos" [f. 131a] y en la Tragedia Policiana (1547) figura ya la expresión en el sentido que nos interesa: "Hija mía, lumbre de mis ojos, báculo de mi cansada vejez" [p. 20b], que define el DHLE como "Persona que es arrimo o consuelo de otra, gralm. anciana o desvalida. Frec. en la expr. de la vejez u otras similares".

La expresión báculo de su vejez aparece también en el Guzmán de Alfarache:

Naciera una hermana, arrimo de mi madre, báculo de su vejez, columna de nuestras miserias, puerto de nuestros naufragios ${ }^{8}$.

Pero seguramente a Cervantes, tal vez como a Alemán, le pudo llegar a través de textos intermedios como el citado de Guevara, como si de un lugar común se tratara cuando se hablaba de la esperanza que los padres depositaban en los hijos, porque la expresión aparece otra vez en de las Epístolas familiares, de Guevara:

Ana, muger de Tobías el viejo y madre de Tobías el moço lloraba la ausencia de su hijo con lágrimas irremediables, diciendo: “¡Ay de mí, ay de mí, hijo mío Tobías, lumbre de nuestros ojos, báculo de nuestra vejez, consolación de nuestra vida, esperança de nuestra casa! ${ }^{9}$

Por último, es curioso señalar que también el falso Quijote escoge la expresión:

Dad, mi bien, un millón de gracias al cielo por la merced que nos ha hecho agora en darnos hijo que, siendo heredero de nuestra hazienda, pueda ser báculo de nuestra senectud, consuelo de nuestros trabajos y alegría de todas nuestras aflicciones ${ }^{10}$.

7. Epístolas familiares. Ed. José María de Cossío. Madrid, Real Academia Española, 1950-1952, II, p. 159. Diferentes críticos, pero en especial MárQUEZ VILLANUEVA [1973: 183-257], han mostrado el aprovechamiento de Guevara por parte de Cervantes y otros contemporáneos.

8. Benito BRANCAFORTE en su edición del Guzmán de Alfarache anota que se trata de un texto que pertenece a una letanía a la Virgen (Madrid, Akal, 1996, p. 96).

9. Ed. cit., f. 42.

10. Ed. Martín de Riquer. Madrid, Espasa-Calpe, 1972, II, p. 62. 
Y en otra ocasión la pone en boca de Sancho, que se lamenta por la pérdida de su asno:

¡Ay, asno de mi ánima!, ¿Y qué pecados has hecho para que te ayan llevado de delante mis ojos? Tú eres la lumbre dellos, asno de mis entrañas, espejo en que yo me mirava, ¿quién te me ha llevado? [...] Alivio de mis trabajos, consuelo de mis tribulaciones, tú solo me entendías los pensamientos, y yo a ti, como si fuera tu proprio hermano de leche ${ }^{11}$.

\section{BORRICA DEL HATO}

Se trata ahora de la historia de Cardenio, los pastores están describiendo a don Quijote el comportamiento atormentado del loco, y uno de ellos dice:

Desde allí a algunos días salió al camino a uno de nuestros pastores y, sin decille nada, se llegó a él y le dio muchas puñadas y coces, y luego se fue a la borrica del hato y le quitó cuanto pan y queso en ella traía; y con extraña ligereza, hecho esto, se volvió a emboscar en la sierra [I, 23, p. 282]

Rodríguez Marín no anota la expresión; pero sí Rico, que define: "cabaña donde se recogen los pastores" [1998]; y posteriormente corrige por: "lugar donde se recogen los pastores" [2004] y "refugio de los pastores" [2005]. Pero hay que tener en cuenta que hato se define también como "provisión de comida" (Aut.) y es muy poco probable que esta palabra aluda aquí a un lugar, más bien parece el animal que lleva la comida de los pastores, como podría deducirse de la definición de la palabra que trae Autoridades: "la provisión de comida que los pastores o gañanes llevan para algunos días al lugar o cabaña que tienen destinado".

La expresión borrica del hato o burra del hato es relativamente frecuente en nuestra literatura. Se puede leer, por ejemplo, en las "Coplas sobre la gobernación del reino", del Cancionero de poesías varias:

No ay majada que no enbarga

tu atijo y garauato,

que ya las burras del hato

no pueden lleuar la carga.

$\mathrm{Y}$ rreçelan el cargar

como tienen el sillar

tan lleno de mataduras,

11. Ibíd., I, 136. 
y las albardas tan duras que te abrán de rebellar [f. $142 \mathrm{r}^{\circ}$ ].

Igualmente la utiliza Hernando de Ávila, en el Coloquio de Moisés:

$2^{\circ}$ Pastor Calla, bobo. (Dale un pescoçón.)

Zagal Harre, allá. $1^{\circ}$ Pastor Mentecato, ¿porqué no tienes acato?

¿Asnos hallado en carava?

Zagal No, son curava

que andaba tras de la burra del hato. ${ }^{12}$

En el mismo texto encontramos:

Una cosa me da pena:

y es que voy a tierra ajena

y dexar aqueste trato

y la borrica y el hato,

siendo una burra tan buena [ibíd, p. 335].

Un villancico tradicional, que hoy todavía se canta, dice:

Cuando los pastores vieron

que el Niño quería mamar,

hasta la burra del hato

la quisieron ordeñar"13.

Podría entenderse también como el animal que acompaña al hato de ganado, entendiendo hato como "porción de ganado mayor o menor", según define el DRAE y utiliza Sancho en diversos momentos de la obra. Aun en este caso, habría que suponer que era la borrica que llevaba las provisiones de los pastores, de ahí que Cardenio acudiera a ella para robar la comida.

\section{LA DILIGENCIA ES MADRE DE LA BUENA VENTURA}

Encontramos también lugares paralelos o lugares comunes en algunos pasajes del Quijote como este que señalo a continuación. Tiene que ver con máximas o sentencias, muy abundantes en la obra. Así en el mismo capítulo 43 de la segunda parte, y antes en el 46 de la primera, leemos:

12. Ed. Julio Alonso Asenjo. Valencia, UNED-Universidad de Sevilla-Universidad de Valencia, 1995, p. 301.

13. [http://usuarios.lycos.es/lacasadelarbol/2Cancionero.htm]. Hoy existe hoy Burrajato como topónimo (por "burra del hato") en Chipiona, Cádiz.

ANALES CERVANTINOS, VOL. XXXVII, PP. 141-165, 2005. ISSN: 0569-9878 


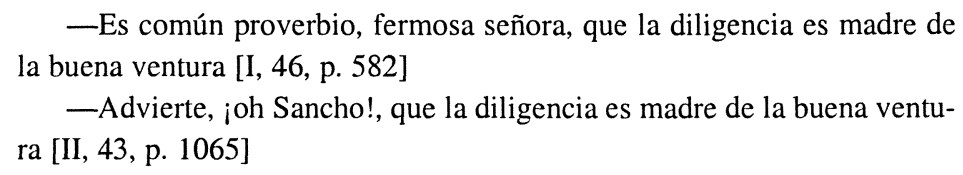

La edición de Rico, 2004 señala que el proverbio modifica levemente unas palabras de San Agustín y que "la frase es lugar común". En efecto, se encuentra en Juan de Aranda, Lugares comunes de conceptos, dichos y sentencias: "La diligencia es madre de la buena ventura" (Sevilla, Juan de León, 1595, f. $\left.151 \mathrm{v}^{\mathrm{o}}\right)$.

\section{LLOVER DIOS REINOS}

Es Sancho el que habla, en esta ocasión de su mujer, porque don Quijote le promete obtener alguna recompensa por el hecho de ser su escudero. Cuando pregunta si a su mujer le correspondería parte del premio como consorte, don Quijote le responde con una pregunta retórica: ¿Quién lo duda? El escudero, entonces, replica:

\footnotetext{
Yo lo dudo -replicó Sancho Panza-, porque tengo para mí que, aunque lloviese Dios reinos sobre la tierra, ninguno asentaría bien sobre la cabeza de Mari Gutiérrez. Sepa, señor, que no vale dos maravedís para reina; condesa le caerá mejor, y aun Dios y ayuda [I, 7, p. 102]
}

Existen expresiones construidas de forma semejante, que recogen los tratadistas de la época, como por ejemplo llover Dios lanzas (Correas), que no es sino una forma de construcción impersonal que se da también con otros verbos de este tipo como amanecer, impersonal por naturaleza, pero que también admite la construcción Amanecerá Dios. Aquí, sin embargo, hay algo más que lo puramente lingüístico, que es lo que nos interesa. Los editores no suelen anotar este pasaje.

Es evidente que Sancho está pensando no en el reino, sino en el símbolo que lo representa por antonomasia: la corona. Aunque lloviesen coronas, ninguna asentaría bien sobre la cabeza de su mujer, porque don Quijote había dicho inmediatamente antes: "Bien podría ser que antes de seis días ganase yo tal reino, que tuviese otros a él adherentes que viniesen de molde para coronarte por rey de uno de ellos". La aparición y repetición de la palabra reino es lo que hace que Sancho construya la frase llover reinos, a imagen y semejanza de otras expresiones en las que llover significa 'repartir el cielo indiscriminadamente un bien, de forma que corresponda al mayor número de personas'.

Pero aquí Cervantes no hace sino seguir la Floresta española de Melchor de Santa Cruz o una fuente común a ambos, cuando se refiere un cuentecillo atribuido a fray Íñigo de Mendoza: 
Fray Íñigo López decía muchas veces: -Aunque llueva mitras, no me caerá una en la cabeza ${ }^{14}$.

Obsérvese que la intención de este personaje es hacer notar que tiene tan mala suerte que aunque las prebendas lluevan del cielo, ninguna le tocaría a él ${ }^{15}$; mientras que Sancho quiere decir que aunque le correspondiese un bien a su mujer, esta no sabría adaptarse a él.

\section{LAS NECEDADES DEL RICO COMO SENTENCIAS PASAN EN EL MUNDO}

Cuando Sancho va como gobernador de su pretendida ínsula, don Quijote le da una serie de consejos, uno de los más importantes es que aprenda a escribir o a firmar por lo menos. El flamante gobernador le responde que al menos sabe firmar con unas letras como de fardo, pero añade:

Y siendo yo gobernador, que es más que ser alcalde, ¡llegaos, que la dejan ver! No, sino popen y calóñenme, que vendrán por lana y volverán trasquilados, y a quien Dios quiere bien, la casa le sabe, y las necedades del rico por sentencias pasan en el mundo, y siéndolo yo, siendo gobernador y juntamente liberal, como lo pienso ser, no habrá falta que se me parezca [II, 43, p. 1066].

Los editores no suelen poner nota al pasaje, pero Sancho -que utiliza la frase como si fuera un refrán, ensartándola detrás de otras expresiones de origen proverbial- ya había relacionado los dos términos, un poco antes, cuando habla de la relación entre Quiteria y Basilio y se atreve a mencionar la "rodaja de la fortuna" y el clavo. Ante la censura de don Quijote por la manifiesta impropiedad de esos términos en su boca, el escudero exclama:

-¡Oh! Pues si no me entienden -respondió Sancho-, no es maravilla que mis sentencias sean tenidas por disparates. Pero no importa: yo me entiendo, y sé que no he dicho muchas necedades en lo que he dicho; sino que vuesa merced, señor mío, siempre es friscal de mis dichos, y aun de mis hechos [II, 19, págs. 857-858].

Ya en la primera parte del Guzmán de Alfarache se encuentra un texto, que expresa una idea similar a la que comentamos:

14. Ed. Maxime Chevalier. Barcelona, Crítica, 1997, págs. 28-29. Es bien conocida la influencia de la Floresta española en Cervantes, como ha anotado Rico en el Quijote a propósito de otros ejemplos [véase Rico, 2004: 824, 872, 1278-79].

15. Sobre fray Íñigo de Mendoza y las peculiaridades de su vida se puede leer la introducción de Julio Rodríguez PUÉRTOLAS a la edición de su poesía en Clásicos Castellanos. 
Es el pobre moneda que no corre, conseja de horno, escoria del pueblo, barreduras de la plaza y asno del rico. Come más tarde, lo peor y más caro. Su real no vale medio, su sentencia es necedad, su discreción locura, [...] ¡Cuán al revés corre un rico! ¡Qué viento en popa! ¡Con qué tranquilo mar navega! ¡Qué bonanza de cuidados! ¡Qué descuido de necesidades ajenas! Sus alholíes llenos de trigo, sus cubas de vino, sus tinajas de aceite, sus escritorios y cofres de moneda. ¡Qué guardado el verano del calor! ¡Qué empapelado el invierno por el frío! De todos es bien recebido. Sus locuras son caballerías, sus necedades sentencias ${ }^{16}$.

Francisco Rico, en su edición de la novela picaresca, recordaba su relación con el Eclesiástico, 13, 27-29; interesa también 13, 26: "Diviti decepto multi recuperatores; locutus est superba et justificaverunt illum: "Humilis deceptus est, insuper et arguitur: locutus est sensate, et non est datus ei locus". El mismo editor apunta su presencia en el Criticón, de Gracián: "La discreción del pobre es necedad y la necedad del poderoso es celebrada"17. José María Micó añade un pasaje de la Ortografía castellana: "Son los filósofos, como pobres, tenidos en poco, y los poderosos de riquezas, aunque humildes y necios, muy levantados" 18 .

Parece, pues, probable que haya que localizar su origen último en estas palabras de la Biblia; pero también se puede encontrar relación, aunque no muy cercana, con un lugar de Horacio que dice: Stultitiam patiuntur opes [Epist., 1, 18, 29], es decir "Las riquezas hacen tolerable la necedad", que de alguna forma ha quedado también como frase hecha ${ }^{19}$.

Provenga de una u otra fuente, debe de ser lugar común, porque algo parecido trae Gracián en El Discreto:

Dora las más veces el oro las necias razones de sus dueños, comunica la plata su argentado sonido a las palabras, de modo que son aplaudidas las necedades de un rico, cuando las sentencias de un pobre no son escuchadas 20 .

Pero las palabras de Sancho, por el contexto en que se dicen, parecen sugerir una corte de aduladores que alabarían sus necedades como sentencias. Han perdido la contraposición entre ricos y pobres y más concretamente entre necedades del rico / sentencias del pobre, porque aquí no interesa la contraposición o porque está implícita.

16. Ed. José María Micó. Madrid, Cátedra, 1992, págs. 375-376.

17. Barcelona, Planeta, 1983, p. 354

18. Ibíd., p. 376.

19. Víctor J. HeRrero LloRente, Diccionario de expresiones y frases latinas. Madrid, Gredos, $1995,3^{\text {a }}$ ed., p. 441 b.

20. "Dirás necedades, y jurará que son sentencias, que ni Séneca las dixera. Dezía mil barbaridades Valente, 4. y las celebravan los aulicos, por flores de Cicerón” [p. 395, en CORDE]. También la recoge Francisco Garau en El sabio instruido en la naturaleza en quarenta máximas, políticas y morales $(1675-91)$. 


\section{OFENDER MIS CASTAS OREJAS}

Cuando Dorotea, convertida en princesa Micomicona, se acerca hasta un don Quijote retirado entre peñas y le adula diciendo que ha llegado su fama hasta sus oídos; el caballero la ataja:

No más: cesen mis alabanzas -dijo a esta sazón don Quijote-, porque soy enemigo de todo género de adulación; y aunque ésta no lo sea, todavía ofenden mis castas orejas semejantes pláticas [I, 29, p. 376]

Es lugar que no suelen anotar los editores, pero Cervantes vuelve a usar la expresión en El coloquio de los perros:

Vamos a verle [al diablo] muy lejos de aquí, a un gran campo, donde nos juntamos infinidad de gente, brujos y brujas, y allí nos da de comer desabridamente, y pasan otras cosas que en verdad y en Dios y en mi ánima que no me atrevo a contarlas, según son sucias y asquerosas, y no quiero ofender tus castas orejas ${ }^{21}$.

La combinación es frecuente en otros autores, también con la forma "orejas castas", "castos oídos", a veces aplicadas a los del cristiano. Es combinación común, en la literatura española la encontramos ya en textos del XVI, como la traducción del Cortesano, de Boscán: "Amancillaría los limpios y castos oídos que me escuchan" [en CORDE]. También aparece en el Fructus sanctorum, de A. de Villegas: "Hizo otras cosas que atormentan oírlas a las orejas castas" [ibíd]. Parece que la expresión existía ya en textos latinos del XV-XVI: "Castas aures inebriantes" aparece en una Oratio in gymnasio[1492], de Conradus Celtis. También el Liber secundus Annalium Conventus Pisani Sanctae Catharinae empieza: "Secundum hunc librum ab anno MCCCCLXXXIX incipio, quia hoc anno nova in Conventu nostro facies, novusque vivendi modus apparuit. Hactenus namque sub cura Romani provincialis fuit, et a multis annis, singulis quod facere magis libuisset licebat, propria possidendo, expendendo, donando, et caetera quae veri domini faciunt pro arbitrio faciendo: caetera taceo, quae castas aures offensura, certo certius scio".

Son muy frecuentes las expresiones ofender las orejas, ofender castas orejas o castos oídos, a veces con el añadido de cristianos; pero existe también ofender las orejas, como usa Nebrija en su Gramática:

Como dize aristoteles por muchas razones avemos de huir los consonantes. La primera por que las palabras fueron halladas para dezir lo que

21. Ed. Florencio Sevilla Arroyo; Antonio Rey Hazas. Alcalá de Henares, Centro de Estudios Cervantinos, 1994, pp. 940-941.

ANALES CERVANTINOS, VOL. XXXVII, PP. 141-165, 2005. ISSN: 0569-9878 
sentimos: \& no por el contrario el sentido a de servir alas palabras. Lo cual hazen los que usan de consonantes enlas clausulas delos versos: que dizen lo que las palabras demandan: \& no lo que ellos sienten. La segunda por que en habla no ai cosa que mas ofenda las orejas: ni que maior hastio nos traiga: que la semejança: la cual traen los consonantes entre $\mathrm{si}^{22}$.

No es infrecuente que aparezca la expresión en prólogos y escritos preliminares de libros, tal como ocurre en la aprobación de la Jocoseria, de Quiñones de Benavente, debida a Fray Juan de Aguilera Ángel: "No hallo en él cosa alguna [....] de suerte que leída pueda ofender las orejas más castas" 23 .

\section{SER LA BOCA MEDIDA}

Estamos ahora en el capítulo 59 de la segunda parte en que Sancho y don Quijote llegan a una venta, después de haber dormido en despoblado. Observemos cómo se imbrica dentro de la narración:

Llegaron, pues, a ella; preguntaron al huésped si había posada; fueles respondido que sí, con toda la comodidad y regalo que pudiera hallar en Zaragoza. Apeáronse y recogió Sancho su repostería en un aposento de quien el huésped le dio la llave, llevó las bestias a la caballeriza, echoles sus piensos, salió a ver lo que don Quijote, que estaba sentado sobre un poyo, le mandaba, dando particulares gracias al cielo de que a su amo no le hubiese parecido castillo aquella venta.

Llegose la hora del cenar, recogiéronse a su estancia; preguntó Sancho al huésped que qué tenía para darles de cenar, a lo que el huésped respondió que su boca sería medida y, así, que pidiese lo que quisiese, que de las pajaricas del aire, de las aves de la tierra y de los pescados del mar estaba proveída aquella venta [II, 59, p. 1211].

Don Quijote desaparece de escena inexplicablemente, aunque Sancho y él habían entrado en la venta; Cervantes se olvida de él y es Sancho el que mantiene un diálogo con el ventero y le pide lo que tuviera de comer para él y su amo. Para su sorpresa, sólo les puede ofrecer una uña de vaca, cosa que el escudero acepta resignado. Termina Cervantes de la siguiente manera:

22. Ed. John O’Neill. Madison, Hispanic Seminary of Medieval Studies, 1995, f. 22.

23. Ed. I. Arellano, J. M. Escuero y A. Madroñal. Madrid, Univ. Navarra-Iberoamericana-Vervuert, 2001, p. 105. 
Ésta fue la plática que Sancho tuvo con el ventero, sin querer Sancho pasar adelante en responderle, que ya le había preguntado qué oficio o qué ejercicio era el de su amo [II, 59, p. 1213].

Es evidente que Cervantes ha utilizado aquí un material previo de probable procedencia folclórica que sucede entre un ventero y un caminante, de ahí la extraña desaparición de escena de don Quijote. Posiblemente es un cuentecillo tradicional (que desarrolla el motivo de "la comida fantasma") de amplio eco también en el teatro breve. Cervantes está convirtiendo en materia narrativa un episodio que perfectamente podría haberse dramatizado en un entremés, tanto por su extensión, como por sus personajes o por el diálogo que mantienen, plagado de exclamaciones, giros populares y frases hechas, que funcionarían perfectamente en escena. Así dice el ventero:

¿Polla? ¡Mi padre! -respondió el huésped-. En verdad en verdad que envié ayer a la ciudad a vender más de cincuenta" [p. 1212].

La viveza y rapidez del diálogo y lo que dicen los personajes lo podríamos encontrar también en un entremés, de hecho lo encontramos al menos en dos piezas, una de ella, titulada Entremés del ventero, de Quiñones ${ }^{24}$, se basa claramente en este episodio del Quijote que protagonizan Sancho y el citado ventero. Aquí es en realidad el gracioso Tristrás el que acaba comiendo un poco de tocino, después de haberle dicho el ventero que podía pedir cualquier manjar, que de todo tenía. La deuda con el Quijote es clara, pero por si acaso el autor escribe una cancioncilla al final, donde alude a don Quijote de la Mancha y Dulcinea del Toboso ${ }^{25}$. La fecha de esta pieza es cercana a 1632 , si no de ese año mismo. Quiñones adapta la obra en otra suya titulada El remediador, donde se dice claramente que lo pone en escena Juan Rana, y en la que el motivo de la comida fantasma sigue siendo el más importante, aunque no el único [ibíd: 106].

Ya María Rosa Lida en su libro El cuento popular y otros ensayos había dado cuenta de esta relación ${ }^{26}$ y Henri Recoules insistió en el aprovechamiento

24. También conocida como Lo que pasa en una venta y atribuido a Belmonte, aunque con menos crédito, según he demostrado en otro lugar [Nuevos entremeses atribuidos, Ed. A. Madroñal. Kassel, Reichenberger, 1996, pp. 105-106].

25. L. Quiñones de Benavente, Nuevos entremeses atribuidos, cit., p. 122.

26. "Sancho y el ventero fantaseador se empeñan en un diálogo chistoso, bastante parecido al que figura en el Entremés el remediador, de Lope, y que más tarde fue malignamente contado por Théophile Gautier (Voyage d'Espagne, 1840) como caso típico de las posadas españolas" (El cuento popular. Buenos Aires, Losada, 1976, p.49). Según M. R. LIDA DE MALKIEL dicho episodio habría servido para dos entremeses del mismo título, El remediador, de Lope y otro así titulado de Quiñones. El error proviene de que El remediador se publica en Fiestas del Santísimo Sacramento (1644) junto con algunas obras del Fénix, pero la pieza es la misma que se publica en la Jocoseria de Quiñones y no hay duda en cuanto a su paternidad. 
textual de la obra cervantina ${ }^{27}$; pero lo que aquí mantengo es un paso más: que Cervantes en realidad pudo adaptar este entremés para convertirlo en episodio de la novela, en paso, aprovechando la terminología de Lope de Rueda de la que deriva directamente. Porque, por si fuera poco, el carácter dramático se acentúa por la deuda que sin duda tiene con un paso del batihoja, el llamado La tierra de Jauja, donde se lee:

Honzigera Mira, en la tierra de Xauxa hay un río de miel, y junto a él otro de leche; y entre río y río hay una puente de mantequillas encadenada de requesones, y caen en aquel río de la miel, que no paresce sino que están diziendo: “¿Cómeme, coméme!”28.

Cejador escribe en su Fraseología a propósito de la expresión serle su boca medida: "Que se le dará cumplimiento en todo y gusto" y cita a Correas [I, p.178]. Rico en 2004 explica la expresión como "que le serviría a pedir de boca". Pero ser la boca medida aparece ya en el siglo XV, en las poesías de Antón de Montoro, y se repite con frecuencia a lo largo de los siglos XVI y XVII. Explica Aut. que Su boca es o será la medida es "frase con que se da facultad a alguno para que pida cuanto quisiere, pues todo se le dará". Y Correas dice:

Su boka será su medida o Su boka será medida. Ke se le dará kunplimiento i gusto en todo. El otro, usando desta frase komo suena, a una bestia ke llevava prestada metióla la boka en un medio zelemín, i ansí kunplía kon ella i kon dezir: Su boka será medida.

Rodríguez Marín explica que "Ser, o haber de ser, medida la boca de uno es frase muy usual que equivale a obtener cuanto pidiere" [1948: VIII, p.13]. Remite al Entremés de vizcaíno fingido:

-Dice que, con lo dulce, también bebe vino como agua [...] y que beberá otra vez.

-Y aun otras ciento: su boca puede ser medida 29 .

Es curioso notar que este pasaje cervantino sucede justo en el capítulo 59 de la segunda parte, cuando por primera vez se enjuicia la continuación falsa de Avellaneda. El estudioso Edward Riley escribió hace algunos años que el "contenido anecdótico [de este pasaje] no parecía dar una justificación suficiente de

27. Henri ReCoules, "Cervantes y Timoneda y los entremeses del siglo XVII", en $B B M P$, XLVIII (1972), pp. 231-291, en especial 231-238.

28. Pasos. Ed. José Luis Canet. Madrid, Castalia, 1992, p. 151.

29. Miguel de CervanTES: Teatro completo. Ed. Florencio Sevilla Arroyo y Antonio Rey Hazas. Barcelona, Planeta, 1987, p. 792. 
su presencia" y que "se halla distante con respecto a las líneas principales de la acción y los temas identificados" 30 . Riquer señaló que Cervantes imitaba a su rival, pero Riley va más allá al señalar que Cervantes "no está parodiando toda la escena" del falsario Avellaneda, aunque la "compuso [...] con su rival en mente". Estoy absolutamnte de acuerdo, pero tal vez haya que añadir que lo que hace es intentar una vuelta de tuerca, el más difícil todavía, en suma, demostrar que es mejor que su rival con las mismas armas; recrea el mismo episodio, pero lo hace infinitamente más gracioso: echa mano de la tradición folklórica y literaria que conoce y recuerda una pieza dramática en la que aparece la comida fantasma y la tierra de Jauja. No lo tenía muy difícil, en la Sobremesa y alivio de caminantes (1563) de Timoneda aparece el cuentecillo "A buen capellán, mejor sacristán", cuando a un caminante que sólo ha olido el humo que sale de un palomino que se está comiendo un cura se le exige que pague su parte de la comida, ante lo cual decide pagar con el sonido de unas monedas. El cuentecillo de amplia trayectoria folclórica, pues se recoge entre los sefardíes de Marrue$\cos ^{31}$ y en otros sitios, influyó sin duda en un paso del siglo XVI, tal vez del propio Lope de Rueda (que también desarrolla en otro el tópico de la tiera de Jauja), porque no de otra forma se explica su dramatización por parte de Quiñones en los dos entremeses citados del XVII. A Cervantes tal vez le bastó con la primera parte.

\section{SOBRE COBRAR MI HACIENDA}

La escena ahora se sitúa en la venta, cuando el barbero expoliado reconoce sus pertenencias al ver el rucio de Sancho y quiere recuperar lo que le han robado, momento en que exclama el barbero, dirigiéndose al escudero:

— ¡Ah, don ladrón, que aquí os tengo! ¡Venga mi bacía y mi albarda, con todos los aparejos que me robastes!

Sancho, que se vio acometer tan de improviso y oyó los vituperios que le decían, con la una mano asió de la albarda, y con la otra dio un mojicón al barbero que le bañó los dientes en sangre; pero no por esto dejó el barbero la presa que tenía hecha en el albarda; antes, alzó la voz de tal manera que todos los de la venta acudieron al ruido y pendencia, y decía:

30. Edward C. RiLEY: “Uñas de vaca o manos de ternera'. Cervantes y Avellaneda”, en La rara invención: estudios sobre Cervantes y su posteridad literaria. Barcelona, Crítica, 2001, pp. 107-114. Las citas de las pp. 107, 108, 109, 111.

31. Cfr. Ángel GonZÁlez Palencia, "Con la ilusión basta", en Historias y leyendas. Estudios literarios. Madrid, CSIC, 1942, pp. 145-160. Doy las gracias desde aquí a mi colega Paloma Díaz-Mas por llamarme la atención sobre este particular. Lo he tratado con mayor detenimiento en la comunicación "Los entremeses intercalados en el Quijote", presentada al congreso El Quijote y el pensamiento teórico-literario (Madrid, junio de 2005, en prensa). 
- ¡Aquí del rey y de la justicia, que sobre cobrar mi hacienda me quiere matar este ladrón, salteador de caminos!

-Mentís -respondió Sancho-, que yo no soy salteador de caminos, que en buena guerra ganó mi señor don Quijote estos despojos [I, 44, p. 568]

Riquer explica la expresión sobre cobrar mi hacienda como equivalente de: "Además de quedarse con" [2003: 477]; Rico sigue esa anotación, aunque matizada: "Además de haberme quitado mis bienes" [1998, 2004], pero creo que también se puede entender otra cosa: "Por el hecho de querer recuperar lo que es mío", puesto que cobrar significa eso: "exigir lo que se debe, recuperar" (Aut.). Es verdad que la lógica del discurso actual parece aconsejar la lectura primera: no solo le han quitado lo que le pertenece, es que además le quiere matar el propio ladrón; pero hay que entender también la lógica de los hechos que se expresan en la novela: el barbero expoliado en I, 21, ha salido corriendo cuando le embestía don Quijote para quitarle el yelmo-bacía, no sabe que Sancho le ha despojado, sólo que iba con el caballero que le acometió. Ahora encuentra su albarda en rucio ajeno y entiende que su dueño debe de ser quien se la quitó, y es cuando quiere recuperarla cuando le acomete Sancho. Cervantes sugiere una relación causa-efecto inmediata: Sancho quiere matar al barbero por haber intentado recuperar lo que le pertenece, de ahí la injusticia manifiesta; no se trata, pues, de decir a quien le quiera oír que primero le robaron sus pertenencias y ahora le quieren matar.

No es la única vez que la expresión aparece en la obra, justamente después de haber provocado desperfectos en la venta, el ventero sale tras la pareja protagonista para cobrar su hacienda, es decir, para obtener lo que le pertenece, la ganancia que le compensaría por tanto gasto y tanto desperfecto. Don Quijote le responde que por ser venta y no castillo aquella le perdone la paga. Entonces contesta así el primero a don Quijote:

Poco tengo yo que ver en eso -respondió el ventero-. Págueseme lo que se me debe y dejémonos de cuentos ni de caballerías, que yo no tengo cuenta con otra cosa que con cobrar mi hacienda [I, 17, p. 200].

Es decir, 'obtener, recuperar lo que me pertenece'. De la misma manera Cervantes escribe en Rinconete y Cortadillo:

Y, cuando dijo al arriero que les había oído decir que los naipes que traían eran falsos, se pelaba las barbas, y quisiera ir a la venta tras ellos a cobrar su hacienda, porque decía que era grandísima afrenta, y caso de menos valer, que dos muchachos hubiesen engañado a un hombrazo tan grande como él ${ }^{32}$.

32. Novelas ejemplares, ed. Florencio Sevilla Arroyo y Antonio Rey Hazas. Alcalá de Henares, Centro de Estudios Cervantinos, 1994, p. 565. 
También aquí, como se ve, es 'recuperar algo obtenido de forma ilícita'. La expresión aparece en bastantes textos contemporáneos, como el de fray Diego de Ocaña, Relación de un viaje por América:

La gente es mucha y todos soldados y sin oficios; no entienden sino el pasear, y con muy poquita ocasión, luego meten mano a las espadas, y lo ordinario es por el juego y las mujeres; y las más veces por cobrar los hombres sus haciendas, que en pidiéndole a uno lo que le prestaron, si no le aguardan todo lo que él quiere, luego desafía al otro para que se mate con él sobre cobrar su hacienda. Y así se levantan los unos con las haciendas de los otros [p. 196].

También se puede encontrar en la Historia de la conquista de México, de Antonio de Solís:

Levantaron las áncoras y prosiguieron su viaje hasta que llegaron a un promontorio o punta de tierra introducida en la jurisdicción del mar, que al parecer se enfurecía con ella sobre cobrar lo usurpado, y estaba en continua inquietud porfiando con la resistencia de los peñascos.

\section{TENER CUATRO DEDOS DE ENJUNDIA / TENER EL PADRE ALCALDE}

En los inicios de la segunda parte, Sancho conversa con un Sansón Carrasco que le pone objeciones a la afirmación de que podía gobernar ínsulas:

-Mirad, Sancho -dijo Sansón-, que los oficios mudan las costumbres, y podría ser que viéndoos gobernador no conociésedes a la madre que os parió.

-Eso allá se ha de entender -respondió Sancho- con los que nacieron en las malvas, y no con los que tienen sobre el alma cuatro dedos de enjundia de cristianos viejos, como yo los tengo" [II, 4, p. 721]

De la misma forma, cuando le dicen al alcalde Benito Repollo de El retablo de las maravillas, que solo podrá ver el retablo si es hijo de legítimo matrimonio o si no tiene raza de confeso exclama:

-A mi cargo queda eso, y sele decir que, por mi parte, puedo ir seguro a juicio, pues tengo el padre alcalde; cuatro dedos de enjundia de cristiano viejo rancioso tengo sobre los cuatro costados de mi linaje ${ }^{33}$.

Sancho también había dicho:

33. Teatro completo, p. 173. 
Bien sé firmar mi nombre -respondió Sancho-, que cuando fui prioste en mi lugar aprendí a hacer unas letras como de marca de fardo, que decían que decía mi nombre; [...] y teniendo yo el mando y el palo, haré lo que quisiere, cuanto más que el que tiene el padre alcalde... Y siendo yo gobernador, que es más que ser alcalde, jllegaos, que la dejan ver! [I, 43, p. 1066]

Rodríguez Marín da cuenta sucintamente de esta relación, que limita a lo puramente verbal [1948: IV, p. 117]. En otro lugar he tratado de mostrar la deuda que tienen entre sí los dos personajes cervantinos: Benito Repollo y Sancho, ambos gobernadores ${ }^{34}$. Es como si Cervantes hubiera pensado en que alguno de los rasgos de uno se podían trasvasar al otro personaje para dotarle de características similares. Agustín de la Granja ha defendido con convincentes razones la anterioridad del entremés ${ }^{35}$, pero aunque este fuera posterior a la segunda parte del Quijote, es claro que entonces sería Sancho el que hubiera suministrado algunas de sus características para la construcción del personaje dramático.

Como Sancho, Repollo es labrador y hombre casado; la mujer del segundo se llama Teresa Repollo para recordar más si cabe a la Teresa del primero ${ }^{36}$. Como este, Repollo también utiliza frecuentes prevaricaciones lingüísticas y así dice ciceronianca por ciceroniana ${ }^{37}$ y, cuando le corrigen, replica que "siempre quiero decir lo que es mejor, sino que las más veces no acierto" (ibíd.). Tampoco entiende los latines, e interpreta un per omnia por Antoña [ibíd., p. 172]. Como Sancho, Repollo es crédulo y se expresa con tono malhumorado; también exclama frecuentemente: "cuerpo de tal", "cuerpo del mundo", "hi de puta y como se vuelve la mochacha" [ibíd., pp. 176 y 179] y utiliza eufemismos graciosos, como "me ha calado el agua hasta la canal maestra" [ibíd., p. 178], que se parecen mucho a los que utiliza el narrador para referirse al escudero de don Quijote: "Hizo su operación el brebaje y comenzó el pobre escudero a desaguarse por entrambas canales" $[\mathrm{I}, 17, \text { p. 198] }]^{38}$.

34. A. Madroñal: "Entre Sancho Zancas y Juan Rana”, en Luciano García LorEnzo (ed.), La construcción de un personaje: el gracioso, Madrid, Fundamentos, 2005, pp. 245-298.

35. "La fecha de composición de El retablo de las maravillas", en Anales Cervantinos, 34 (1998), pp. 255-267.

36. Todavía una relación más encontramos entre los nombres de Pero Panza y Sancho Repollo, que aparecen en el "Romance pastoril de la elección del alcalde de Bamba", incluido en el Thesoro de varias poesías (1580), de Pedro de Padilla, como nota AsEnsio [1971: 101]. Leemos en dicho romance: "Pues que Pero Pança, el viejo, / atamó [sic] ya su jozgado, / que Sancho Repollo diga, / como más empergeñado, / para her alcalde nuevo/ quién tendrá maxín más craro" [Madrid: Francisco Sánchez, 1580, f. 351. Modernizo la acentuación y puntuación del texto].

37. Teatro completo, p. 171.

38. Rico explica bien el pasaje, como "vomitar y sufrir diarrea". 


\section{LA VIDA COMO COMEDIA O JUEGO DE AJEDREZ}

En el capítulo 12 de la segunda parte asistimos a una conversación entre caballero y escudero que nos habla de la adquirida discreción del segundo, conforme va transcurriendo la obra. Don Quijote y Sancho se han encontado con la carreta de representantes y, de pronto, se ponen a filosofar sobre lo que es la vida. El caballero dice entonces:

Ninguna comparación hay que más al vivo nos represente lo que somos y lo que habemos de ser como la comedia y los comediantes; si no, dime: ¿no has visto tú representar alguna comedia adonde se introducen reyes, emperadores y pontífices, caballeros, damas y otros diversos personajes? Uno hace el rufián, otro el embustero, este el mercader, aquel el soldado, otro el simple discreto, otro el enamorado simple; y acabada la comedia y desnudándose de los vestidos della, quedan todos los recitantes iguales. [...]

El escudero le replica:

-Brava comparación -dijo Sancho-, aunque no tan nueva, que yo no la haya oído muchas y diversas veces, como aquella del juego del ajedrez, que mientras dura el juego cada pieza tiene su particular oficio, y en acabándose el juego todas se mezclan, juntan y barajan, y dan con ellas en una bolsa, que es como dar con la vida en la sepultura. [II, 12, p. 784]

Rodríguez Marín señala la posible fuente directa: los Diálogos de la vida cristina de fray Héctor Pinto ${ }^{39}$. Rico ha apuntado, siguiendo a varios estudiosos, el carácter emblemático del pasaje; que este puede haber sido interpolado con posterioridad para desmentir a Avellaneda y a su caracterización de Sancho; que denota los modos de aprendizaje "de oídas" del Sancho auténtico y que, en último término, también se pone la vida en el tablero de ajedrez en la poesía de Joge Manrique [2004, II: p. 476]. Pero yo creo, con Riquer [2003: 641], que hay una fuente más cercana para este lugar cervantino, se trata de una oración fúnebre que el predicador fray Alonso Cabrera dedicó a la muerte de Felipe II. Dice así:

Es la tierra el teatro en que se representan las farsas humanas; permanece firme, esta se queda como la casa de las comedias; pasa una generación y viene otra, como diferentes compañías de representantes. ¿Qué es ver un personaje de rey en una comedia? ¡Qué acompañado, qué servido, qué aderezado! Acabada la farsa, es un hombre bajo de por ahí. [...]

39. En realidad, se trataría de la traducción que de ellos hizo Gonzalo de Illescas, Segunda parte de Imagen de la vida christiana [1576], edición de Alcalá, 1595. Cita los ff. 360 (el mundo es como una farsa) y 278 (juego del ajedrez). 
Es un juego de ajedrez, que entabladas las piezas, tiene cada una su lugar y preminencia: el rey, la dama, el arfil; pero acabando el juego y echadas en la bolsa, y revueltas como caen: el rey, que es más pesado, abajo, el peón arriba, no hay diferencia ni respeto 40

Observemos que ambas comparaciones aparecen prácticamente seguidas, como en el Quijote, incluso aparece una alusión al estiércol ${ }^{41}$, palabra que utiliza Sancho poco después para señalar que la conversación de su amo está haciendo fertilizar su entendimiento. Algo que Clemencín censuraba en Cervantes, por la impropiedad que suponía su aparición cuenta se refería a "temas morales con estilo sublime" [Rico, 2004 II: 476].

\section{CONCLUSIÓN}

Hemos señalado la influencia de diversas obras sobre Cervantes, pero es de sobra sabido que el Quijote influye también en sus lectores, no solo desde el punto de vista literario, también desde el puramente lingüístico. Ya se ha escrito mucho sobre la importancia que la obra tiene en la lexicografía académica del Diccionario de Autoridades, y también en la Gramática, etc. Pero mi propósito ahora es detenerme en algunos lugares concretos, que no son los más sabidos: el enderezar entuertos o Con la Iglesia hemos topado, frases que se han hecho famosas con un sentido que no les había dado Cervantes porque ni siquiera aparecen así en la obra.

Me quiero centrar para concluir en otros dos lugares no tan conocidos, como son uno del capítulo 26 de la segunda parte, cuando don Quijote da por terminado el retablo de Maese Pedro de una forma bastante violenta. Dice así el narrador:

Diciendo y haciendo, desenvainó la espada y de un brinco se puso junto al retablo, y con acelerada y nunca vista furia comenzó a llover cuchilladas sobre la titerera morisma, derribando a unos, descabezando a otros, estropeando a este, destrozando a aquel, y, entre otros muchos, tiró un altibajo tal, que si maese Pedro no se abaja, se encoge y agazapa, le cercenara la cabeza [II, 26, pp. 917 y 929$]$ ].

Observemos que aquí no se enuncia una frase que se hizo famosa a partir del XVIII: No dejar títere con cabeza. La frase aparece como tal por primera vez en el sainetero Ramón de la Cruz:

40. Fray Alonso de CABRERA, "Oración fúnebre que predicó en la muerte de Felipe II" (en NBAE, 1906, III , pp. 694-695).

41. "El que poco antes, dice Orígenes, se sentaba en el trono real, ahora está sentado en un montón de estiércol" (Fr. Alonso de Cabrera, op. cit., p. 696b). 
Ponce. Esta noche al amo de ésta

no le queda en el vasar

un títere con cabeza. 42

Lo usan también, entre otros, Alvarado, Bécquer, Galdós, etc. José Ma Iribarren, en esa obra famosa que se titula El porqué de los dichos, trata de este en particular y alude al Quijote, cuando dice que lo puso en práctica en este momento de la obra, pero sin decir que puede ser su origen, que es lo que sostengo aquí.

Para terminar, conviene citar unas palabras que don Quijote dirige a su escudero, porque apenas ha podido descabezar el primer sueño, mientras que Sancho ha dormido a pierna suelta toda la noche. Podrían constituir un ejemplo perfecto de la diferente disposición que ambos tienen hacia la vida en general. El caballero se dirige a él y le dice:

Maravillado estoy, Sancho, de la libertad de tu condición: yo imagino que eres hecho de mármol o de duro bronce, en quien no cabe movimiento ni sentimiento alguno. Yo velo cuando tú duermes, yo lloro cuando cantas, yo me desmayo de ayuno cuando tú estás perezoso y desalentado de puro harto [II, 68, p. 1179]

Esta curiosa contraposición, "Yo velo cuando tú duermes", es una magnífica muestra de antítesis para los estudiosos de la lengua y estilo de Cervantes, como han destacado Hatzfeld y Rosenblat. Se trata de un octosílabo que prácticamente adapta Bécquer en un verso de su rima XXVII:

Despierta, tiemblo al mirarte;

dormida, me atrevo a verte.

Por eso, alma de mi alma,

yo velo mientras tú duermes.

Lo cierto es que el texto de Cervantes parece sugerir la presencia de unos versos subyacentes que tienden a la medida octosilábica (con la excepción del último e introduciendo algunas leves variantes) y que tienen formulación sentenciosa. Su influjo en la mejor literatura española no deja de ser un indicio más de la trascendencia de esta obra imperecedera que conocemos hoy con el nombre del hidalgo loco que la protagoniza.

42. Ramón de la Cruz, La plaza Mayor, 1765, en CORDE.

ANALES CERVANTINOS, VOL. XXXVII, PP. 141-165, 2005. ISSN: 0569-9878 


\section{BIBLIOGRAFÍA}

\section{Ediciones anotadas}

ACADEMIA [2004]: Don Quijote de la Mancha, ed. Real Academia Española. Madrid: Alfaguara, 2004.

AMORÓs, ANDRÉs [1999]: El ingenioso hidalgo Don Quijote de la Mancha. Madrid: Ediciones SM, 1999.

Clemencín, Diego [1833-39]: El Ingenioso Hidalgo Don Quijote de la Mancha comentado por Don Diego Clemencín. Madrid : [s.n.], 1833-1839 (E. Aguado, Impr.). 6 v.

Cortejón, Clemente [1905-13]: El ingenioso hidalgo Don Quijote de la Mancha. Primera edición crítica. Barcelona: Impr. La Académica, 1905-13. 6 v. [No se publicó el Diccionario proyectado].

GaOS, ViCENTE [1987]: El ingenioso hidalgo don Quijote de la Mancha; edición crítica y comentario. Madrid: Gredos, 1987. 3 vols.

MuRILLO, LuIS ANDRÉS[1978]: El ingenioso hidalgo don Quijote de la Mancha. Madrid: Castalia, 1978. 2 vols. Vol. III: Bibliografía fundamental. Madrid: Castalia, 1982, $2^{\mathrm{a}} \mathrm{ed}$.

Pedraza, Felipe B. [2004]: Don Quijote de la Mancha. Madrid: Algaba Ediciones, 2004.

Rico, Francisco ET AL. [1998]: Don Quijote de la Mancha. Barcelona: Crítica, 1998, 2 vols. $1 \mathrm{CD}$.

-[2001]: Nueva ed. en 1 vol. Barcelona: Crítica, 2001.

-[2004]: Nueva ed. Círculo de Lectores-CECE, 2004. 2 vols. 1 CD.

- [2005]: Nueva ed. Toledo: Junta de Comunidades de Castilla-La Mancha.

RIQUer, MARTín DE [1990]: El ingenioso hidalgo Don Quijote de la Mancha. Barcelona: Planeta, 1990. [1 $1^{\text {a }}$ ed. 1944]. Ed. revisada y actualizada, 2003.

- [2004a] Ilustrada por Mingote. Barcelona: Planeta, 2004. 2 vols.

- [2004b] Ilustrada por Saura. Barcelona: Círculo de Lectores, 2004. 2 vols.

RodríGuez Marín, Francisco [1947-49]: El Ingenioso Hidalgo Don Quijote de la Mancha. Nueva edición crítica con el comentario refundido y mejorado y más de mil notas nuevas por F. Rodríguez Marín. Madrid: Ediciones Atlas, 1947-1949. [1ª ed. 1911-13].

Sabor de Cortázar, Celina-Lerner, Isaías [1969]: Don Quijote de la Mancha. Pról. de Marcos A. Morínigo. Buenos Aires: Editorial Universitaria, 1969, 2 vols.

-[2005]. Buenos Aires: Eudeba, 2 vols.

Schevill, Rodolfo -Bonilla, Adolfo [1928-1941]: Don Quixote de la Mancha. Madrid: Gráf. Reunidas, 1928-1941. 4 v.

Sevilla Arroyo, Florencio [2004]: El ingenioso hidalgo Don Quijote de la Mancha.Barcelona: Lunwerg, 2004.

-Rey Hazas, Antonio [1993]: El ingenioso hidalgo Don Quijote de la Mancha. Alcalá de Henares: Centro de Estudios Cervantinos, 1993.

\section{Notas}

Bradford, Carlos F.: Índice de las notas de Diego Clemencín en su edición de El Ingenioso Hidalgo Don Quijote de la Mancha (Madrid, 1833-39, 6 vols., $4^{\circ}$ ). Madrid: Real Academia Española, 1885.

Givanel Más, JoÀn: Doce notas para un nuevo comentario al Don Quijote. Madrid: Imp. del Asilo de huérfanos del S. C. de Jesús, 1920. 
Hartzenbusch, JuAn Eugenio: Las 1633 notas puestas por D. Juan Eugenio Hartzenbusch a la primera edición de El ingenioso hidalgo reproducida por D. Francisco López Fabra con la foto-tipografía. Barcelona: Estab. tip. de Narciso Ramirez y Cía., 1874.

S. Cortázar, Celina E Isaías Lerner: "Notas al texto del Quijote". En Filología (Buenos Aires), X, 1964, pp. 187-205.

\section{Nuevas herramientas}

http://www.donquixote.com/lzxico.html

Bibliografía analítica cervantina (Eduardo Urbina, 1999): http://www.ucm.es/info/especulo/numero13/bib_cerv.html

Biblioteca Digital Cervantina. Cervantes Project 2001. Eduardo Urbina: http://www.csdl. tamu.edu/cervantes/spanish/spanindex.html

CORDE $=$ Corpus Diacrónico del Español (www.rae.es)

El ingenioso hidalgo don Quijote de la Mancha. Facsímil electrónico de las princeps de 1605 y 1615: http://www.csdl.tamu.edu/cervantes/spanish/ctxt/princep

FERNÁNDEZ, JAIME: Bibliografía del Quijote por unidades narrativas y materiales de la novela. Alcalá de Henares : Centro de Estudios Cervantinos, 1998 (1 CD-ROM).

NTLLE=RAE: Nuevo tesoro lexicográfico de la lengua española. (2 DVD. Consulta parcial en la página www.rae.es)

Obras completas de Miguel de Cervantes. Ed. electrónica de Fred Jehle y E. Urbina de las Obras completas de Rudolph Schevill y Adolfo Bonilla. Octubre 1996. http://www. ipfw.indiana.edu/cm1/jehle/web/cervante.htm

TESO $=$ Teatro Español del Siglo de Oro. Chadwyck-Healey. CD.

\section{Estudios}

Academia Española, Real: “Glosario”. En ed. Academia, 2004, pp. 1157-1235.

CEJADOR Y FRAUCA, JULIO: La lengua de Cervantes: gramática y diccionario de la lengua castellana en el Ingenioso Hidalgo Don Quijote de la Mancha. Madrid: Jaime Ratés, 1905-1906, 2 v. (El segundo dedicado al léxico).

-Fraseología o estilística castellana. Madrid: Imp. Rev. Archivos, 1921-1925, 4 v.

ECheverRía y Reyes, ANíbal: Vocabulario de El ingenioso hidalgo don Quijote de la Mancha compuesto por Miguel Cervantes y Saavedra. Santiago: Prensas de la Universidad de Chile, 1932.

FERnÁNDEZ Gómez, CARLos: Vocabulario de Cervantes. Madrid: Real Academia Española, 1962

HatzFeld, Helmut A.: El "Quijote" como obra de arte del lenguaje. $2^{\mathrm{a}}$ ed. española ref. y aum. reimp. Madrid: CSIC, 1972 [1 $1^{\mathrm{a}}$ ed. en alemán, 1927; en español, 1949].

Hernández Herrero, JuAn: El léxico del Quijote. Barcelona: Gráficas 85, 1996.

Lacarta, Manuel: Diccionario del Quijote. Madrid: Alderabán, D.L. 1994.

LERNER, IsAíAs: “Anotar otra vez el Quijote". En Cervantes: estudios en la víspera de su centenario. Kasse: Reichenberger, 1994, p.299-308.

—: "El Quijote y la construcción de la lengua literaria áurea". En Cervantes. Alcalá: CEC, 1995, pp. 295-310.

—: "El Quijote palabra por palabra". En Edad de Oro, XV, 1996, pp. 63-74 
Montero Reguera, José: El “Quijote" y la crítica contemporánea. Alcalá de Henares: Centro de Estudios Cervantinos, 1997.

Pascual, José Antonio: "Los registros lingüísticos del Quijote: la distancia irónica de la realidad”, en ed. Academia, 2004, pp. 1130-1138.

Rojo, Guillermo: "Cervantes como modelo lingüístico", en ed. Academia, 2004, pp. $1122-1130$.

Rosenblat, Ángel: "La lengua de Cervantes". En Cervantes (Caracas), 1949, pp. 47-129.

— "La lengua de Cervantes". En Suma cervantina (1973), Juan B. Avalle-Arce y Edward C. Riley, ed., p. 323-355.

—: La lengua del Quijote [1971] . Madrid: Gredos, 1995.

\section{Resumen}

Este trabajo presenta interpretaciones nuevas a determinadas palabras o expresiones del Quijote, identificación de fuentes o lugares paralelos de pasajes concretos y la influencia de algunas palabras y expresiones en obras posteriores. Presenta también una bibliografía relacionada con el léxico de la obra.

Palabras clave: Fuentes, notas, influencia, léxico, nuevas interpretaciones, bibliografía

\section{Summary}

This paper presents new interpretations to certain words or expressions in Quijote, and identifies sources or parallel equivalent of concrete passages as well as the influence of some words or expressions in later works. It also has a bibliography of words.

Key words: Sources, notes, influence, new interpretations, bibliography. 